\title{
Internacionalização da cachaça paraibana
}

The internalization of cachaça from he state of paraiba

Guilherme Martins de Brito Cavalcanti ${ }^{1}(\mathbb{D})$, Vinicius Farias Moreira ${ }^{2}(\mathbb{D})$ e Yákara Vasconcelos Pereira ${ }^{3}$

${ }^{1}$ Universidade Federal de Campina Grande (UFCG), pós-Graduando em Gestão Estratégica de Negócios, email: guilhermemcavalcanti@gmail.com

${ }^{2}$ Universidade Federal de Campina Grande (UFCG), Doutor em Administração, email: vinicius.farias@professor.ufcg.edu.br

${ }^{3}$ Universidade Federal de Pernambuco (UFPE), Doutora em Administração, email: yakara.pereira@ufpe.br

\section{RESUMO}

O artigo tem por objetivo descrever o potencial de internacionalização da cachaça paraibana e identificar mercados-alvo. Classificado como uma pesquisa qualitativa, estudo de caso descritivo, empírico e usando dados secundários, desenvolveu-se a partir da análise documental de dois relatórios técnicos das plataformas Trade Map, Comex Stat e Comtrade Database. Verificou-se que a participação da Paraíba nas exportações brasileiras está muito aquém da sua capacidade, sinalizando que há muito a crescer. A análise de dados sinalizou países como Alemanha e Paraguai como sendo os mercados mais promissores para investimentos no comércio internacional por parte dos produtores paraibanos.

Palavras-chave: Internacionalização. Exportação. Mercado-alvo. Cachaça. Paraíba.

\section{ABSTRACT}

The article aims to describe the potential of internationalization of the cachaça of Paraiba and to identify target markets. Classified as a qualitative research, a descriptive, empirical case study using secondary data was developed through the documentary analysis of two technical reports, elaborated from the Trade Map, Comex Stat and Comtrade Database platforms. It was verified that the participation of Paraíba in the Brazilian exports is well below its capacity, signaling that there is much to grow. Data analysis has signaled countries like Germany and Paraguay as the most promising markets for investments in international trade by the Paraíbaan producers.

Keywords: Internationalization. Export. Cachaça. State of Paraiba. 


\section{INTRODUÇÃO}

A necessidade de crescimento e a busca por resultados significativos vêm impulsionando as organizações quanto à possibilidade de explorar mercados promissores, muitas vezes para além de suas fronteiras geográficas. Nesse cenário, observa-se forte direcionamento à internacionalização das empresas (MAJOCCHI et al., 2005; RICUPERO; BARRETO, 2007). O fenômeno em tela pode ser compreendido por quatro aspectos inter-relacionados: crescimento substancial do comércio internacional; aumento do investimento direto estrangeiro; papel central das empresas multinacionais como produtoras na economia global; e formação de redes internacionais de produção. (CASTELLS, 1999; DICKEN, 2010).

É crescente o interesse em estudos voltados para processos de internacionalização de empresas diante de um cenário de globalização econômica no campo de Gestão Internacional (BARKEMA; BELL; PENNINGS, 1996; JOHANSON; VAHLNE, 1997; REZENDE; SERPA, 2008; RODRIGUES et al., 2012). No contexto brasileiro, tem-se as seguintes pesquisas: Fiat et al. (2013) analisaram as características do processo de internacionalização de pequenas e médias empresas de base tecnológica, incubadas e graduadas buscando identificar o papel das incubadoras nesse processo; Bueno e Domingues (2011) avaliaram as estratégias de internacionalização utilizadas por seis empresas brasileiras comparando-as com alguns dos modelos de internacionalização; Cahen (2014) levou em consideração a internacionalização de organizações do setor público e desenvolveu proposições que combinassem por que empresas estatais se internacionalizam, com destaque às motivações dessas empresas e principais consequências gerenciais da sua internacionalização.

Apesar da internacionalização ser um fenômeno cada vez mais presente no vocabulário organizacional, muitas empresas, no Brasil, ainda enxergam esta prática como uma espécie de "fuga" para eventuais crises, mentalidade que vem sendo transformada na medida em que ocorre a devida conscientização do empresário por meio de ações governamentais e de demais instituições. Quanto às micro e pequenas empresas (MPE) brasileiras, estas ainda possuem uma tímida participação no mercado internacional, ora devido à falta de consciência exportadora, ou oportunidade de acesso ao conhecimento necessário à consecução de projetos neste sentido.

Alguns programas institucionais de apoio à internacionalização brasileira têm colaborado na inserção de pequenos e médios negócios na agenda de exportação nacional. Esses programas analisam os negócios em potencial e trabalham em consultorias específicas para dar condições de 
competitividade aos interessados. Considerando a realidade do mercado paraibano em potencial para internacionalização, este trabalho destacou o setor de cachaça.

No Brasil, a cachaça ocupa a segunda colocação de bebida alcoólica mais consumida e representa $72 \%$ do mercado de destilados. Já no âmbito mundial, a cachaça figura entre as quatro bebidas destiladas mais consumidas (IBRAC, 2018).

A Paraíba é o maior produtor de cachaça de alambique do Brasil, são 80 engenhos legalizados que produzem a bebida. Segundo a Associação Paraibana dos Engenhos de Cachaça de Alambique - ASPECA (2018), a Paraíba encontra-se em segundo lugar em número de produtores, atrás apenas do estado de Minas Gerais. A produção do estado chega a 12 milhões de litros anuais, em que a cultura de fabricação da cachaça movimenta a economia de modo significativo, pois, os engenhos produtores são responsáveis por cerca de mil empregos diretos e dois mil indiretos (ASPECA, 2018). Surge, nesse contexto, o seguinte questionamento de pesquisa: Como intensificar o potencial exportador da cachaça paraibana?

Neste estudo, considera-se a importância cultural do setor produtivo da cachaça e o fato da indústria de bebidas ser um importante segmento econômico nacional; ponderando-se também que possui desafios, como aumentar em número as exportações, a consolidação no mercado internacional e a batalha diante do reconhecimento internacional da cachaça como uma bebida genuína e exclusivamente brasileira. Para nortear o desenvolvimento do referido estudo, tem-se como objetivo descrever o potencial de internacionalização da cachaça paraibana e identificar mercados-alvo.

Por conseguinte, avança-se para uma abordagem teórica acerca das teorias comportamentais (Modelo de Uppsala e Teoria de Redes) e econômicas (Paradigma Eclético de Dunning) da internacionalização, acompanhado da metodologia utilizada, dos resultados e das considerações finais.

\section{FUNDAMENTAÇÃO TEÓRICA}

O interesse pelas operações de internacionalização vem crescendo não apenas entre os empresários e investidores, mas também entre acadêmicos. O conceito de internacionalização tende a ser usado para descrever "[...] o movimento de saída nas operações internacionais de uma empresa individual ou de um grupo maior" (WELCH; LUOSTARINEN, 1999, p. 84). 
Utilizando-se de um conceito mais amplo, a internacionalização pode ser definida como: “[...] o processo de aumentar o envolvimento em operações internacionais" (WELCH; LUOSTARINEN, 1999, p. 84). A vantagem de utilizar uma definição mais ampla do conceito é que permite considerar os dois lados do processo, ou seja, inward and outward, em que as operações são desenvolvidas no mercado externo e os fluxos de transações realizadas no mercado de origem, envolvendo estruturas e agentes externos.

Goulart, Arruda e Brasil (1994) entendem a internacionalização como um processo crescente e continuado de envolvimento de uma organização em transações com países não pertencentes a sua base de origem. Andersen (1997), por sua vez, define internacionalização como o processo de adaptação das transações comerciais para os mercados internacionais.

\subsection{TEORIAS DO PROCESSO DE INTERNACIONALIZAÇÃO}

As teorias que tratam do processo de internacionalização ao longo das últimas décadas podem ser classificadas de acordo com a sua perspectiva de análise. Neste sentido, é possível delimitar dois grandes eixos: o primeiro é o econômico, especialmente o que foi desenvolvido no quadro das teorias de negócios internacionais. Esta perspectiva serviu de fundamento para desenvolver diferentes abordagens da internacionalização das empresas, especialmente no que diz respeito ao fenômeno do surgimento das empresas multinacionais (EMNs) e análise dos determinantes e estratégias de investimentos diretos no exterior - IDE. Neste campo destacam-se as teorias da organização industrial (HYMER, 1960), a teoria da internalização (BUCKLEY; CASSON, 1976) e o paradigma eclético (DUNNING, 2000).

O segundo, pesquisadores da Universidade de Uppsala, especialmente na década de 1970, focalizam o interesse de análise do processo de internacionalização com base nas teorias comportamentais (HÖRNELL; VAHLNE; WIEDERSHEIM-PAUL, 1973; JOHANSON; WIEDERSHEIM-PAUL, 1974; JOHANSON; VAHLNE, 1977, 1990). Neste trabalho, enfatizaram-se, particularmente, as abordagens comportamentais para a análise do processo de internacionalização das Pequenas e Médias Empresas - PME’s. 


\subsubsection{Teorias Econômicas e o Paradigma Eclético de Dunning}

A Teoria do Paradigma Eclético foi desenvolvida por John Dunning em 1976, porém só foi publicada em 1988. Segundo o autor, as empresas que procuram se internacionalizar podem realizar esse processo de duas maneiras: 1) produzindo no seu país de origem, fazendo uso de recursos nacionais e suprindo a demanda internacional com exportações; e 2) produzindo em um país estrangeiro, utilizando recursos internacionais e suprindo a demanda internacional diretamente (DUNNING, 1988; 2000).

De acordo com a teoria, quando uma empresa busca o processo de internacionalização, ela deve possuir sobre seus concorrentes, ou eventuais concorrentes do mercado exterior, determinada vantagem competitiva. É importante ressaltar que a decisão, por parte de uma empresa, de produzir ou não seus produtos em outro país, passa por uma avaliação econômica de internalizar seus processos no país-alvo ou de vender os direitos sobre a vantagem competitiva conquistada para alguma empresa local (HEMAIS; HILAL, 2004).

O Paradigma Eclético também conhecido como o Paradigma OLI apresenta três tipos de vantagens competitivas que podem ser consideradas como pré-requisitos para que o processo de internacionalização ocorra em uma empresa, são elas: 1) vantagem de propriedade (Ownership), que faz referência aos ativos, tangíveis e intangíveis, possuídos pela organização capazes de gerar renda; 2) vantagem de localização (Location), referente aos fatores de localização não transferíveis de uma localização e que sejam essenciais para exploração da sua vantagem competitiva, como o custo da mão de obra, barreiras tarifárias ou presença de concorrentes; e a 3) vantagem de internalização, referindo-se ao motivo pelo qual as empresas devem optar por desenvolver internamente sua competência central (core competence) ou adquirir nos mercados externos (DUNNING, 2001).

Stal e Campanário (2010) mostraram como as políticas públicas constituem um componente importante da variável "localização", do paradigma eclético de Dunning, especialmente para os países emergentes, mediante a análise da Lei de Informática; Macadar (2009) analisou os fluxos mundiais de IDE e a participação brasileira nos mesmos. Além disso, descreveu os principais motivos que induzem as empresas a investirem no exterior e discutiu as características das mais destacadas transnacionais brasileiras e gaúchas; e, Coelho e Oliveira Junior (2015), na forma de ensaio, refletiram sobre o fenômeno da internacionalização como um mediador das relações entre 
governos e empresas em contexto de ampla competição internacional, dada uma realidade econômica global.

\subsubsection{Teorias Comportamentais e o Modelo de Uppsala}

O Modelo de Uppsala fundamenta-se no pressuposto de que o processo de internacionalização de empresas se concede de maneira sucessiva e incremental, sendo visto como uma consequência do crescimento e da saturação da empresa no mercado interno, associado às hesitações e deficiências das informações sobre um novo mercado, e pelos quais as empresas projetam realizar investimentos nos mercados internacionais.

O Modelo de Uppsala é estruturado nos conceitos de racionalidade limitada e de aversão ao risco (CARNEIRO; DIB, 2007). As ideias iniciais da racionalidade limitada e da aversão ao risco constituíram dois mecanismos importantes geradores de mudança no processo de internacionalização de empresas, são eles: o conhecimento e o comprometimento. Assim sendo, com o propósito de evitar riscos, as empresas tendem a se internacionalizar na medida que vão obtendo conhecimento, mediante experiências vividas, sobre o mercado exterior sob o qual desejam atuar (JOHANSON; VAHLNE, 1977).

No Modelo de Uppsala, o processo de internacionalização de empresas é efetuado utilizando-se os conceitos de cadeia de estabelecimento e de distância psíquica. Quando se trata da cadeia de estabelecimento proposta, pressupõe-se a existência de quatro estágios, sequenciais, dentro do processo de internacionalização: 1) atividades de exportação esporádicas; 2) atividades de exportação por meio de representantes no exterior; 3) estabelecimento de escritório de vendas próprios; e 4) produção local. Essas quatro etapas da cadeia de estabelecimento vão evoluindo, em uma ordem crescente, em relação ao compromisso da empresa com o mercado exterior, ao conhecimento adquirido sobre o mercado e à complexidade das atividades da empresa nos mercados internacionais (JOHANSON; WIEDERSHEIM-PAUL, 1975).

Celano et al. (2016) problematizaram o fenômeno ainda pouco explorado da distância psicológica a partir da visão dos empregados estrangeiros de uma organização transnacional, ampliando o escopo do trabalho de Rocha (2005; 2007), o qual aborda apenas a distância psicológica dos executivos brasileiros em relação à expansão de negócios para mercados internacionais e não considera o caminho contrário desta mesma distância, ou seja, o sentimento que separa os empregados estrangeiros da matriz de sua empresa em outro país. Chiavegatti e 
Turolla (2011) por meio de ensaio teórico, revisitaram a evolução do modelo de internacionalização de Uppsala e inseriram neste contexto a proposição de Lemos Johanso e Vahlne (2010), em que o risco desempenha papel central, embora seja negligenciado pela literatura de negócios internacionais, mesmo quando se aplica o processo de Uppsala.

Portanto, para que haja uma redução na distância psíquica entre dois mercados, se faz necessário a existência de elevado nível de conhecimento sobre o país-alvo por parte da empresa. Tornando mais fácil para as organizações, que desejam se internacionalizar, optarem por mercados que possuem uma menor distância psíquica em comparação ao seu mercado interno, para que posteriormente, após atingir certo nível de conhecimento, comprometimento e maturidade, possam buscar por mercados com distâncias psíquicas maiores.

\subsubsection{Teoria de Redes}

No ano de 2009, Johanson e Vahlne publicaram um artigo revisando o Modelo de Uppsala original para poder realizar uma adaptação à nova realidade enfrentada. A principal mudança identificada foi que se fazia necessário adotar uma visão da organização como participante de uma rede de relacionamentos, e não mais como um agente isolado, devido à importância do assunto e o envolvimento de Johanson na evolução da literatura (JOHANSON; MATTSSON, 1988).

Hemais e Hilal (2003) consideram a Teoria de Redes (Networks) como um aperfeiçoamento natural do Modelo de Uppsala, dando ênfase ao aspecto relacional durante o processo de internacionalização das organizações. A proposta elaborada por Johanson e Mattsson (1988) estabelece o mercado como uma rede de relacionamentos marcada pela interdependência entre as organizações.

O processo de internacionalização na Teoria de Redes, segundo Johanson e Mattsson (1988), seria a determinação ou estreitamento das relações já existentes com os parceiros em mercados internacionais, buscando almejar os objetivos econômicos da organização. E, para que estes objetivos sejam alcançados da maneira mais satisfatória, existem três formas de se determinar ou estreitar as relações: 1) Extensão internacional, presente quando a organização busca estender relações do mercado nacional ao mercado estrangeiro; 2) Penetração, a qual pode ser identificada quando a organização aumenta o nível de comprometimento dos recursos para entrar em um novo mercado; e 3) Integração internacional, podendo ser evidenciada quando a empresa busca aumentar a coordenação do seu posicionamento em diversas redes.

Ciências Sociais Aplicadas em Revista, v. 20, n. 38, p. 1-22, semestral, janeiro-junho, 2020. 
Figueiredo e Grieco (2013) propuseram um modelo para as relações entre as atividades de inovação, sobretudo aberta, e a internacionalização de empresas em redes; Amal et al. (2008) analisaram o processo de internacionalização de duas médias empresas brasileiras, com o objetivo de compreender como a rede de relacionamento influenciou neste processo; Borini e Ferreira (2015) analisaram como as teorias de redes e institucional ajudam a compreender a internacionalização dos periódicos, e como a análise do fenômeno da internacionalização dos periódicos levanta novas proposições para o processo de internacionalização quando analisado por essas duas perspectivas teóricas.

Portanto, pode-se afirmar que a Teoria de Redes é útil quando se busca explicar o processo de internacionalização de pequenas empresas, que visam entrar em novos mercados fazendo uso dos recursos e do conhecimento agregado das suas redes de negócio. Por isso, o sucesso de uma empresa no mercado internacional depende muito das estratégias que envolvam não somente seus movimentos individuais, mas, também a interdependência de seus relacionamentos dentro da rede e as características culturais dos países-alvo selecionados pela extensão internacional (COVIELLO; MUNRO, 1995).

\section{PROCEDIMENTOS METODOLÓGICOS}

Este estudo pode ser classificado com uma pesquisa qualitativa, seguindo as orientações de Patton (2002), enquadrando-se como um estudo de caso descritivo (MERRIAM, 1998; YIN, 2010), empírico e fazendo uso de dados secundários.

Quanto à coleta de dados para o desenvolvimento deste estudo, optou-se pela análise documental de dois relatórios técnicos emitidos pela Agência Brasileira de Promoção de Exportações e Investimentos (Apex-Brasil), que atua promovendo os produtos e serviços brasileiros no exterior e busca atrair investimentos estrangeiros para setores estratégicos da economia brasileira (APEX BRASIL, 2018).

Os dados utilizados nesta pesquisa, sobre a internacionalização da cachaça, foram colhidos do site Trade Map, uma plataforma desenvolvida pelo International Trade Centre (ITC) que auxilia no desenvolvimento de análises de mercados, fornecendo indicadores sobre o desempenho de exportações, demanda internacional, mercados alternativos e mercados competitivos (INVEST\&EXPORT BRASIL, 2018); o site Comex Stat, ferramenta desenvolvida pelo Ministério da Indústria, Comércio Exterior e Serviços (MDIC), que surgiu em substituição ao antigo Alice 
Web, e trata-se de um sistema que fornece dados detalhados das exportações e importações brasileiras, com base nas declarações dos exportadores e importadores (COMEX STAT, 2018); e, do site Comtrade Database, que é uma ferramenta de livre acesso a dados do comércio internacional e tabelas analíticas relevantes (COMTRADE, 2018).

Para restringir os dados mundiais coletados delimitou-se o Sistema Harmonizado (SH) 220840 - Rum e outras aguardentes de cana. O SH é uma metodologia adotada mundialmente para facilitar as negociações comerciais internacionais a partir da categorização das mercadorias e baseia-se em uma estrutura de códigos de seis dígitos (capítulos, posições e subposições) e as respectivas descrições (MDIC, 2018).

É importante levar em consideração que os dados sobre o SH 220840 não traz informações exclusivas no âmbito da cachaça, devido ao fato de também englobar outros produtos, como é o caso do rum. Porém, os valores que são encontrados nas pesquisas podem ser úteis, visto que evidenciam a maneira como o setor no qual a cachaça está inclusa se comporta no mercado mundial.

Inicialmente coletaram-se dados estatísticos relacionados à exportação e importação mundial para o SH 220840 durante os anos de 2013-2017, posteriormente descreveu-se os principais países importadores/exportadores destes produtos do mundo, do Brasil e da Paraíba, e, confrontando com os maiores importadores mundiais, foi possível selecionar dois mercados-alvo para uma possível internacionalização das cachaças paraibanas, e ao fim, são apresentadas as principais feiras internacionais do setor.

\section{ANÁLISE DOS RESULTADOS}

A análise dos resultados deste estudo foi referente ao SH 220840 - rum e outras aguardentes de cana, e se encontra dividida em três partes: 1) descrição dos dados históricos, nos cenários mundial, Brasil e Paraíba sobre a exportação e importação do SH 220840 durante os anos de 20132017; 2) seleção de países-alvo; e 3) sugestões de feiras internacionais.

\subsection{DADOS HISTÓRICOS DAS EXPORTAÇÕES E IMPORTAÇÕES DO SH 220840}

Segundo o site Trade Map (2018), durante o período observado (2013-2017) a importação e a exportação mundial do SH 220840 cresceu. As exportações chegaram ao seu ápice no ano de 2017 quando atingiu o valor de US\$ 1.410.797.000, e as importações tiveram elevação no ano de 
2013, com o valor de US\$ 1.695.294.000, como é possível observar na Figura 1, apresentada a seguir.

Figura 1 - Gráfico das exportações e importações mundiais do SH 220840

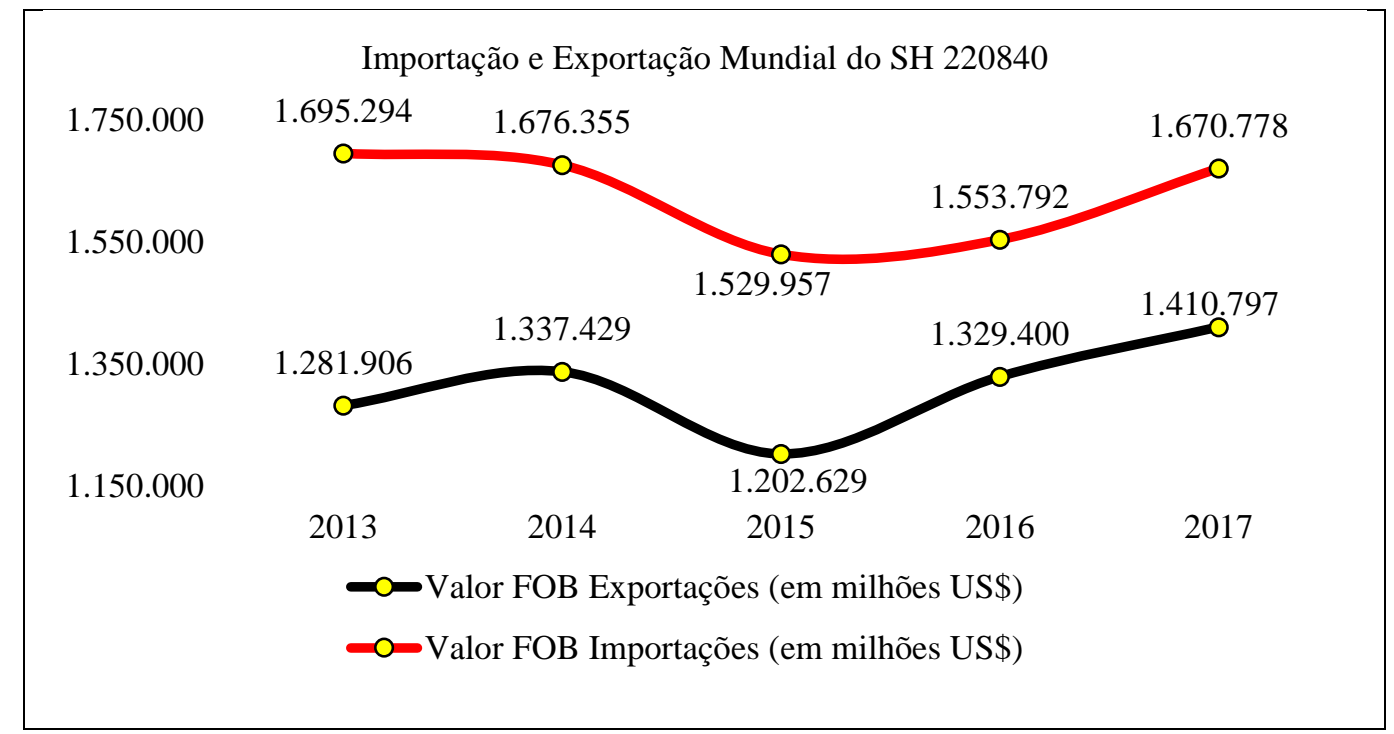

Fonte: Elaboração dos autores, baseada na fonte Trade Map (2018).

No último ano do período analisado (2017), ainda segundo o Trade Map (2018), os cinco países que mais exportaram produtos SH foram, respectivamente: Alemanha, Estados Unidos, Cuba, Espanha e Itália. A Alemanha lidera esta lista com US\$ 203.525.000, com uma participação de $14 \%$ no mercado mundial e com 29.764.471 litros exportados. Enquanto que o Brasil ocupa a $21^{\mathrm{a}}$ posição do ranking com US\$ 15.808 .000 e 8.747.048 litros exportados (TRADE MAP; COMTRADE, 2018), representando pouco mais de $1 \%$ do mercado mundial.

Esses números justificam-se pelo fato de a cachaça ser apenas reconhecida e protegida, de fato, como um produto originalmente brasileiro por três países: Estados Unidos, Colômbia e México (IBRAC, 2018). Esta defasagem indica que ainda há espaço para a exportação direta dos produtos brasileiros para os seus consumidores, visto que, segundo o IBRAC (2018), no que se refere à cachaça, o Brasil tem uma capacidade produtiva de 1,2 bilhão de litros.

Os cinco principais países importadores do SH 220840 no ano de 2017 foram, respectivamente: Alemanha, Espanha, Itália, Estados Unidos e Reino Unido (TRADE MAP, 2018). Novamente, a Alemanha se encontra no topo da lista com um valor de US\$ 315.244.000 e 37.424.085 litros exportados (TRADE MAP; COMTRADE, 2018), representando, aproximadamente, $19 \%$ do mercado mundial. Segundo o site Comtrade (2018), os três principais 
países que exportaram para a Alemanha, no ano de 2017, foram, nesta ordem: Estados Unidos (US\$ 158.604.000 e 12.723.231 litros), Espanha (US\$ 29.392.000 e 5.962.132 litros) e México (US\$ 19.940.000 e 1.213.813 litros). O Brasil ficou na décima terceira posição, tendo exportado para a Alemanha US\$3.626.000 e 1.628.561 litros, o que representa pouco mais de $1 \%$ do total importado.

Com o intuito de restringir as informações coletadas para este estudo sobre as importações e exportações do SH 220840, apresenta-se os dados históricos das importações e exportações do Brasil para este SH. Segundo o site Comex Stat (2018), nos últimos cinco anos (2013-2017), as exportações brasileiras do SH 220840 alcançaram o ponto mais alto em 2014, quando atingiu US\$ 18.335.420 e 10.183.313 litros exportados (COMEX STAR; COMTRADE, 2018), como pode-se observar na Figura 2.

Figura 2 - Gráfico das exportações e importações brasileiras do SH 220840.

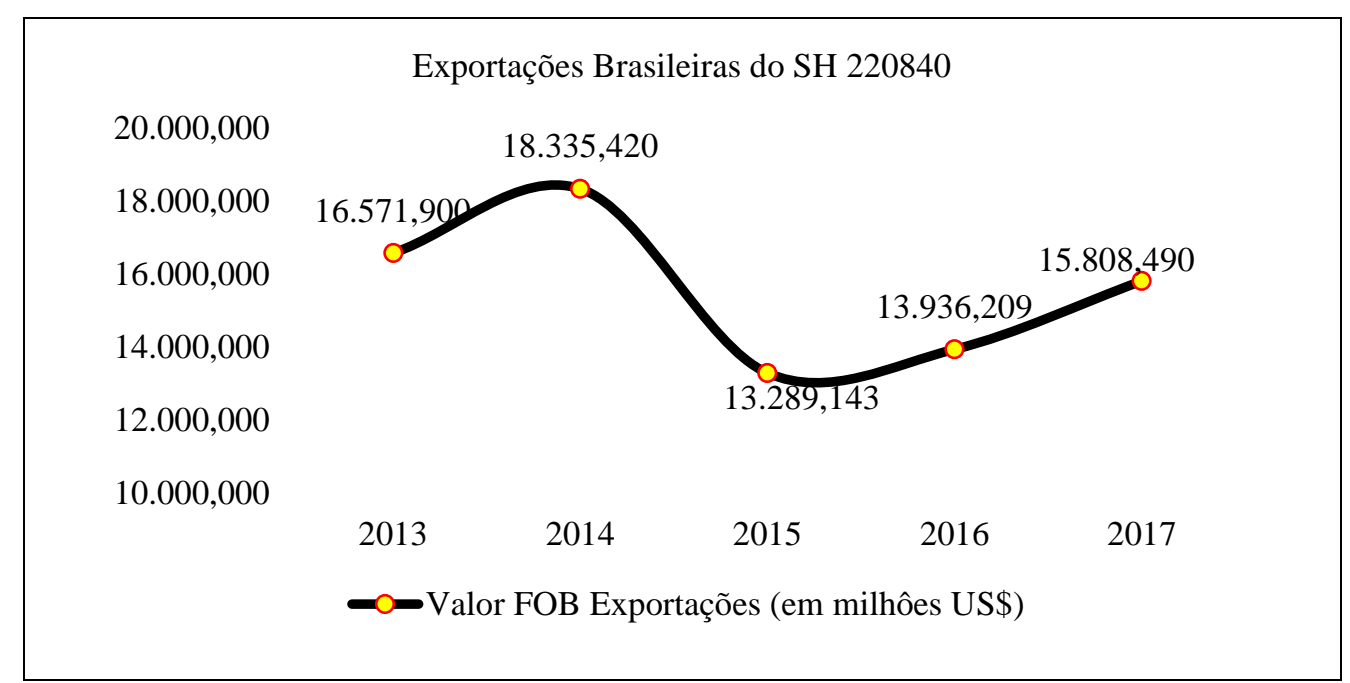

Fonte: Elaboração dos autores, baseado na fonte Comex Stat (2018).

De acordo com os dados disponibilizados no Comex Stat (2018) apresentados na Figura 2, e acompanhando a tendência das exportações mundiais apresentadas na Figura 1, as exportações brasileiras do SH 220840 também atingiram menor valor em 2015, chegando a US\$13.289.143 e 7.772.990 litros exportados.

No entanto, é possível perceber que de 2015 em diante as exportações brasileiras têm crescido, passando para US\$ 15.808.490 e 9.217.312 litros exportados em 2017 (COMEX STAR; COMTRADE, 2018), elevação de quase 19\%. Esse crescimento é justificado pela ação da ApexBrasil em conjunto com o IBRAC por meio do Projeto Setorial de Promoção às Exportações de Cachaça "Cachaça: Taste the new, Taste Brasil", que atraíram investimentos em mais de R\$ 1,3 
milhão nas ações exportadoras, gerando a presença de mais de 50 empresas (APEX BRASIL, 2018).

Para o ano de 2017, ainda segundo o Comex Stat (2018), o Brasil exportou US\$15.808.490 e 8.747.048 litros (COMTRADE, 2018), e os cinco países para onde o Brasil mais exportou os produtos do SH 220840 foram, nesta ordem: Estados Unidos, Alemanha, Paraguai, França e Portugal. Neste ano, os Estados Unidos importaram do Brasil um total de US\$2.795.976 e 778.084 litros (COMTRADE, 2018). A Alemanha, que figurou o segundo lugar, importou US\$ 2.757.330 e 1.874.602 litros; o Paraguai, terceiro lugar, US\$ 1.937 .738 e 1.922 .837 litros; França, quarto lugar, US\$ 1.144.725 e 714.698 litros; e Portugal, em quinto lugar, US\$1.055.269 e 595.315 litros (COMEX STAT; COMTRADE, 2018).

É importante ressaltar que durante os anos de 2013-2016 a Alemanha foi quem liderou a lista de maiores países importadores do Brasil do SH 220840, tendo sido ultrapassada pelos Estados Unidos apenas no ano de 2017, e que o Paraguai vem crescendo significativamente neste cenário, passando do $5^{\circ}$ lugar em 2013 com US\$ 1.174.200 e 1.088.944 litros exportados, para $3^{\circ}$ lugar em 2017 com US\$ 1.937 .738 e 1.922.837 litros exportados (COMEX STAT; COMTRADE, 2018).

Segundo o Comex Stat (2018), no ano de 2017, os cinco estados brasileiros que mais exportaram os produtos do SH 220840 foram: São Paulo, Rio de Janeiro, Pernambuco, Paraná e Ceará. A Tabela 1 apresenta o estado, sua colocação, o valor de exportação e sua representatividade frente às exportações brasileiras no ano, e o principal destino das exportações, com seu valor e representatividade frente às exportações do estado.

Tabela 1 - Cinco maiores estados brasileiros exportadores do SH 220840

\begin{tabular}{l|cccccc}
\hline$\#$ & ESTADO & $\begin{array}{c}\text { VALOR EM } \\
\text { US\$ (FOB) }\end{array}$ & $\%$ & $\begin{array}{c}\text { PRINCIPAL } \\
\text { DESTINO }\end{array}$ & $\begin{array}{c}\text { VALOR EM } \\
\text { US\$ (FOB) }\end{array}$ & $\%$ \\
\hline $\mathbf{1}^{\mathbf{0}}$ & São Paulo & 7.968 .669 & $50,4 \%$ & Estados Unidos & 1.139 .200 & $14,3 \%$ \\
$\mathbf{2}^{\mathbf{0}}$ & Rio de Janeiro & 2.010 .009 & $12,7 \%$ & Alemanha & 781.265 & $38,9 \%$ \\
$\mathbf{3}^{\mathbf{0}}$ & Pernambuco & 1.680 .278 & $10,6 \%$ & Alemanha & 971.471 & $57,8 \%$ \\
$\mathbf{4}^{\mathbf{0}}$ & Paraná & 1.427 .669 & $9 \%$ & Paraguai & 1.027 .912 & $72 \%$ \\
$\mathbf{5}^{\mathbf{0}}$ & Ceará & 1.023 .081 & $6,5 \%$ & Estados Unidos & 339.968 & $33,2 \%$ \\
\hline
\end{tabular}

Fonte: Elaboração dos autores, baseado na fonte Comex Stat (2018).

Observando-se a tabela 1, a soma das exportações dos estados de São Paulo e do Ceará para os Estados Unidos representa, aproximadamente 53\% das importações totais deste país. Já a soma 
das exportações realizadas pelos estados do Rio de Janeiro e Pernambuco representam, aproximadamente, $64 \%$ das importações totais da Alemanha. Isso justifica o fato desses dois países encabeçarem a lista dos maiores importadores dos produtos brasileiros do SH 220840. No que se refere ao estado da Paraíba, até o desenvolvimento desta pesquisa não constavam no sistema do Comex Stat dados referentes às exportações paraibanas no ano de 2017.

Segundo o Comex Stat (2018), nos últimos cinco anos (2013-2017) só foram registradas no sistema exportações dos produtos do SH 220840 produzidos na Paraíba nos anos de 2013 e 2016. Essas exportações atingiram seu ápice no ano de 2013 com US\$ 18.000 e, aproximadamente 6.674 litros exportados, como está apresentado na Figura 3.

Figura 3 - Gráfico das exportações paraibanas do SH 220840.

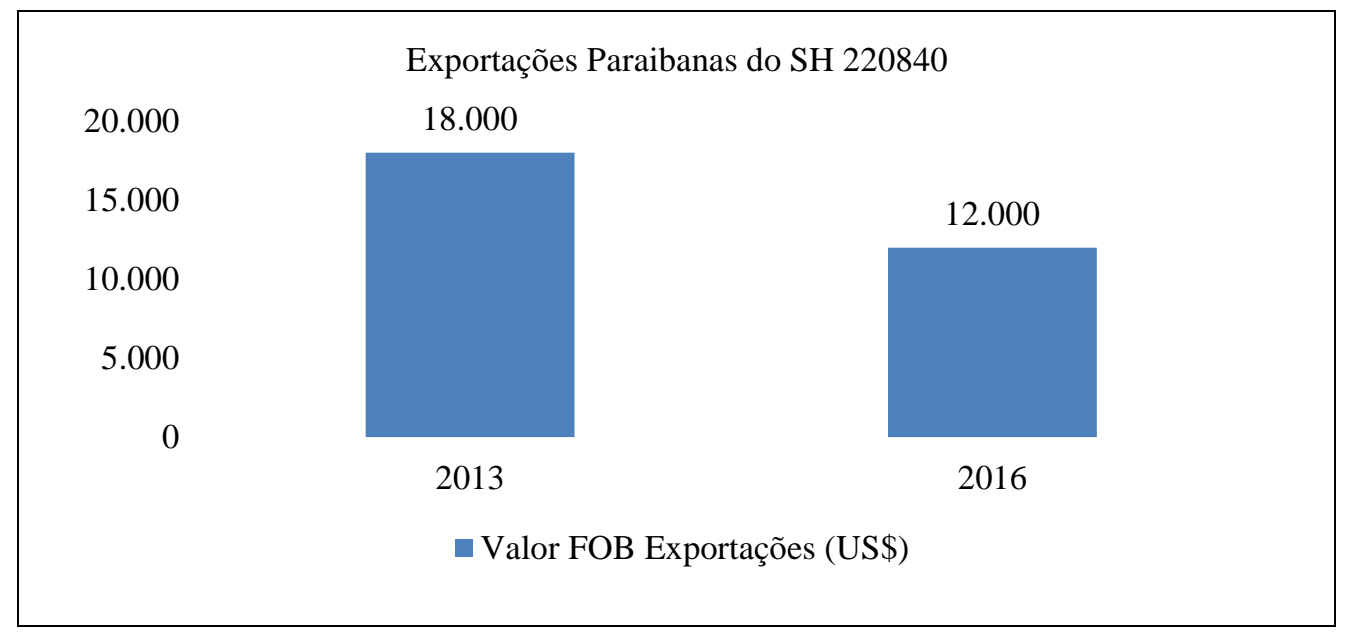

Fonte: Elaboração dos autores, baseado na fonte Comex Stat (2018).

No entanto, no último ano em que houve exportação dos produtos do SH 220840 da Paraíba, 2016, este valor diminuiu para US\$ 12.000 e, aproximadamente, 4.524 litros exportados. Segundo o Sebrae (2016), as exportações, de um modo geral em todos os setores, sofreram quedas neste ano devido à crise econômica do país.

Mesmo com um valor relativamente baixo, a Paraíba figurou entre os 15 estados brasileiros que mais exportaram, ocupando a $11^{\mathrm{a}}$ posição, destinando todas as suas exportações para os Estados Unidos. Entretanto, este valor encontra-se abaixo quando comparado com o que foi exportado pelos estados que se encontram no topo da lista: $1^{\circ}$ São Paulo (US\$ 5.838.478); $2^{\circ}$ Minas Gerais (US\$ 1.901.719); e $3^{\circ}$ Pernambuco (US\$ 1.881.232), e também abaixo das exportações de outros estados nordestinos como o Ceará ( $6^{\circ}$ maior exportador - US\$ 867.861) e a Bahia ( $8^{\circ}$ maior exportador US\$ 70.857) (COMEX STAT, 2018).

Ciências Sociais Aplicadas em Revista, v. 20, n. 38, p. 1-22, semestral, janeiro-junho, 2020. 


\subsection{SELEÇÃO DOS MERCADOS-ALVO}

Esta seção tem a finalidade de apresentar quais foram os mercados-alvo selecionados a partir da descrição e análise dos resultados da pesquisa sobre as importações e exportações dos produtos do SH 220840 no mundo, no Brasil e na Paraíba. Também apresenta uma análise mais abrangente acerca de cada um dos países selecionados.

Portanto, observando-se quão forte a Alemanha é no mercado internacional do SH 220840, marcando presença tanto como importador mundial destes produtos ( $1^{\mathrm{a}}$ colocação) e como destino das exportações brasileiras dos produtos deste SH (1 $1^{\text {a }}$ colocação de 2013 a 2016 e $2^{\text {a }}$ colocação em 2017); o crescimento do Paraguai nas importações dos produtos deste SH produzidos no Brasil e o fato da tarifa de exportação para este país ser de 0\% (TRADE MAP, 2018); e que são produzidos no estado da Paraíba, segundo a ASPECA, cerca de 12 a 13 milhões de litros de cachaça por safra (SILVA, 2017), portanto esses são dois mercados que devem ser explorados pelas empresas produtoras de cachaça da Paraíba.

Diante disto, torna-se possível destacar alguns conceitos que foram abordados no referencial teórico deste trabalho. Primeiramente, destaca-se o conceito da cadeia de estabelecimento definido no Modelo de Uppsala (JOHANSON; WIEDERSHEIM-PAUL, 1975). É importante que a empresa paraibana produtora de cachaça que opte por se internacionalizar siga, de forma gradual e sequencial, cada um dos quatro estágios que compõe esta cadeia. No caso da Alemanha, segundo o Invest\&Export Brasil (2016), já existem empresas alemãs que são representantes exclusivas de marcas brasileiras de cachaça em todo o continente Europeu, ou seja, essas empresas se encaixam no segundo estágio da cadeia de estabelecimento, que é realizar atividades de exportação por meio de representantes.

Em segundo lugar, ainda em relação ao Modelo de Uppsala, destaca-se o conceito da distância psíquica, e recomenda-se que esta seja a mínima possível entre o país de origem e o país do mercado em que se deseja penetrar. E isso é identificado na relação Brasil e Paraguai, pois segundo o Invest\&Export Brasil (2016) esses países são culturalmente bem próximos, possuindo sistema político parecido (presença da Democracia, contemplando a distribuição do poder estatal em três: Executivo, Legislativo e Judiciário); práticas de negócios e de ética similares; uma distância geográfica curta, pois fazem fronteira um com o outro, permitindo uma comunicação mais próxima entre os paraguaios e os brasileiros e menor custo de logística e infraestrutura; e a 
participação de ambos países no Mercosul e no Tratado de Assunção de 1991, que buscava o comprometimento dos países envolvidos na cooperação econômica e integração de projetos políticos.

Em terceiro lugar, destaca-se o conceito do Paradigma Eclético (DUNNING, 1988; 2000) no que diz respeito aos três tipos de vantagens competitivas (propriedade, localização e internalização) que podem ser consideradas como pré-condições para a ocorrência do processo de internacionalização. Tanto para a Alemanha, quanto para o Paraguai, pode-se afirmar que os produtores brasileiros detêm essas vantagens competitivas visto que: no que diz respeito à vantagem de propriedade, estes têm o know-how de todo o processo produtivo, possuem maquinários diferenciados (por muitas vezes caseiros).

No que diz respeito à vantagem de localização, considerando as condições climáticas das principais regiões produtoras de cachaça no Brasil, torna-se possível a instalação do engenho próximo das plantações facilitando assim a logística do processo produtivo; e por fim, a vantagem de internalização é alcançada, mantendo interno o desenvolvimento do core competence, visto que as vantagens de propriedade e localização dificilmente serão alcançadas atuando no mercado externo.

\subsubsection{Características Gerais do Mercado da Cachaça na Alemanha}

Segundo o guia "O Mercado Alemão para Cachaça Brasileira" do site Invest\&Export (2016), na Alemanha existem dois produtos semelhantes a cachaça: o Korn e o Weinbrand, que são destilados feitos de trigo e vinho, respectivamente. Esses também são consumidos em doses ou misturados em drinks e possuem teor alcoólico entre 30-60\%.

A média mundial da taxa de importação do SH 220840 para a Alemanha é de 2,4\%, entretanto, para o Brasil essa taxa, no ano de 2017, foi de aproximadamente 5,8\% (TRADE MAP, 2018). Essa disparidade se dá pelo fato de a Alemanha importar produtos do mesmo SH de países da própria União Europeia, que possui $0 \%$ de taxa de importação.

A distribuição dos produtos exportados pode ser realizada na Alemanha de duas maneiras: 1) empresas produtoras/importadoras de destilados ou 2) empresas importadoras. Ambas modalidades, por já deterem conhecimento acerca da comercialização do produto no mercado local podem facilitar os trâmites legais (INVEST\&EXPORT BRASIL, 2016). Nesse ponto, pode-se novamente ressaltar o segundo estágio da cadeia de estabelecimento do Modelo de Uppsala 
(JOHANSON; WIEDERSHEIM-PAUL, 1975) e também a Teoria de Redes de Johanson e Mattsson (1988), que diz que o processo de internacionalização de uma empresa pode ocorrer por meio de uma rede de relacionamentos marcada pela interdependência entre as organizações.

No que diz respeito a embalagens de transporte e embalagens dos produtos segundo o Invest\&Export Brasil (2016), observa-se de que maneira a cachaça será armazenada para o transporte. Esta pode ser exportada em tanques ou em contêineres em garrafas de $700 \mathrm{ml}$ e/ou 1 litro. Todas as garrafas devem ser rotuladas e empacotadas em caixas de papelão de 6 ou 12 garrafas.

Para o Invest\&Export Brasil (2016), torna-se necessário desenvolver um rótulo respeitando o tamanho certo das letras, descrição dos ingredientes e o teor alcoólico, também deve conter o código barras, e, ademais, deve estar impresso o selo verde conhecido como Grüner Punkt (Ponto Verde). Este é o selo comprovador da participação no Sistema Dual Alemão, o qual comprova que o produtor/importador paga uma taxa para que a empresa executora do sistema faça a coleta e reciclagem das embalagens usadas. Por fim, é aconselhável para as empresas que pretendem internacionalizar seus produtos, que procure a ajuda de um importador para tratar das questões mais burocráticas e seguir as devidas recomendações.

\subsubsection{Características Gerais do Mercado da Cachaça no Paraguai}

Segundo o guia "Como Exportar Paraguai" do site Invest\&Export Brasil (2016), no Paraguai a cachaça possui um concorrente semelhante, trata-se da Caña Paraguaya, que é feita do mel da cana-de-açúcar. No entanto, esta bebida possui teor alcoólico entre $42-45 \%$, sendo consumida de forma diferente da cachaça.

A taxa de importação do SH 220840 para o Paraguai é de, aproximadamente 0\%. Isso se dá pelo fato das importações paraguaias serem, quase em sua totalidade $(91,5 \%)$ oriundas do Brasil, que possui a tarifa de importação de 0\% (TRADE MAP, 2018), isso ocorre, devido à participação dos países no Mercosul.

No quesito relacionado à distribuição dos produtos, também pode-se adotar duas possibilidades descritas na seção que trata das características gerais da Alemanha, incluindo-se a participação de agentes comerciais que vendem os produtos para supermercados e outros varejistas (INVEST\&EXPORT BRASIL, 2016) e sua relação com a Teoria de Redes de Johanson e Mattsson (1988).

Ciências Sociais Aplicadas em Revista, v. 20, n. 38, p. 1-22, semestral, janeiro-junho, 2020. 
Por fim, no que diz respeito à embalagem de transporte, embalagem do produto e rotulagem, segundo o Invest\&Export Brasil (2016), o Paraguai não faz exigências tão burocráticas quanto a Alemanha. Por vezes, solicitam um rótulo traduzido para o espanhol, mesmo que seja em forma de adesivo. Porém, esta medida não é obrigatória para a cachaça.

\subsection{FEIRAS INTERNACIONAIS}

Para que as empresas que buscam se internacionalizar alcancem mais mercados, se faz necessário a participação em feiras e rodadas de negócios. Segundo o Ministério da Agricultura Pecuária e Abastecimento (2018), esse tipo de participação é uma estratégia clássica de promover produtos em outros mercados. Além de reduzir os custos transacionais ao reunir, em um mesmo ambiente, duas partes interessadas na realização de negócios internacionais.

Com o intuito de potencializar a internacionalização das cachaças produzidas na Paraíba, segue no Quadro 1 a indicação de feiras internacionais do SH 220840 nos países-alvo identificados anteriormente.

Quadro 1: Feiras internacionais do SH 220840 nos países-alvo escolhidos

\begin{tabular}{|c|c|c|c|}
\hline FEIRA & CIDADE & DATA & INFORMAÇÕES \\
\hline $\begin{array}{c}10^{\mathrm{a}} \text { Expo Paraguay- } \\
\text { Brasil }\end{array}$ & $\begin{array}{l}\text { Assunção - } \\
\text { Paraguai }\end{array}$ & $\begin{array}{l}26,27 \text { e } 28 \text { de } \\
\text { setembro/2018 }\end{array}$ & $\begin{array}{l}\text { - Participação de } 100 \text { empresas nacionais e } \\
\text { internacionais; } \\
\text { - Participação de Cachaças Brasileiras; } \\
\text { - Campeonato Nacional de Caipirinha. }\end{array}$ \\
\hline $\begin{array}{c}\text { Anuga - Taste the } \\
\text { Future }\end{array}$ & $\begin{array}{l}\text { Colônia - } \\
\text { Alemanha }\end{array}$ & $\begin{array}{c}\text { 05-09 de } \\
\text { outubro/2019 }\end{array}$ & $\begin{array}{l}\text { - } 525 \text { exibidores de } 66 \text { países; } \\
\text { - 71.000 visitantes; } \\
\text { - Participação de cachaças brasileiras; } \\
\text { - Participação da Apex-Brasil. }\end{array}$ \\
\hline
\end{tabular}

Fonte: Elaboração dos autores, baseado na fonte Invest\&Export Brasil (2018).

Seguindo a lógica da Teoria de Redes de Johanson e Mattsson (1988), é nas feiras e rodadas de negócios que a empresa conhecerá parceiros para explorar o processo de internacionalização por meio da interdependência dos agentes, pois terão mais know how sobre o mercado, canais de comunicação do comércio, exigências de embalagens, leis sanitárias e procedimentos alfandegários (INVEST\&EXPORT BRASIL, 2016). 


\section{CONSIDERAÇÕES FINAIS}

Neste estudo foi abordada a importância de se conquistar vantagens competitivas de propriedade, localização e internalização do Paradigma Eclético de Dunning; de encontrar mercados-alvo com a menor distância psíquica possível e seguir os estágios sequenciais da cadeia de estabelecimento, do Modelo de Uppsala; e da interdependência dos atores dentro de uma rede de relacionamentos internacional, proposta pela Teoria de Redes.

Em relação aos mercados-alvo escolhidos para a exportação das cachaças paraibanas, as análises iniciaram-se pela Alemanha que já é identificada com um mercado com as portas abertas para os produtos classificados no SH 220840, visto que é a maior importadora mundial do ano 2017 e maior importadora dos produtos brasileiros nos anos de 2013 a 2016.

Para este mercado cabe-se um trabalho mais bem elaborado visto que a representatividade das exportações brasileiras no mercado alemão chega a pouco mais de 1\%. Já para o segundo mercado-alvo selecionado, o mercado paraguaio, identificou-se uma distância psíquica reduzida, tornando-se assim, um mercado muito atrativo quanto às questões de proximidades culturais e de fácil acesso ao mercado.

Considerando que o Brasil é um país emergente, é importante para as empresas que buscam se internacionalizar procurarem instituições que promovam ações de divulgação de produtos e serviços brasileiros nos mercados internacionais. A partir destas instituições e participações em feiras e rodadas de negócios, as empresas se tornarão qualificadas para atuar em países estrangeiros, alcançando assim novos horizontes para seus produtos.

Dentro deste contexto, recomenda-se como ações futuras para as empresas paraibanas produtoras de cachaça que estreitem suas relações com a Apex-Brasil que possui um núcleo de operações do PEIEX no estado (APEX BRASIL, 2018). Neste programa, a empresa irá passar por um diagnóstico gratuito e ao fim serão apresentadas soluções para as áreas mais deficientes da organização, afim de desenvolver o potencial competitivo no mercado internacional.

$\mathrm{Na}$ elaboração desta pesquisa foram enfrentadas algumas limitações no que diz respeito à classificação do SH incluir o rum, fato que tornou os dados mais abrangentes do que o esperado. Além deste, a indisponibilidade de dados, no sistema do Comex Stat, referentes às exportações paraibanas do SH analisado, no ano de 2017.

Embora esta classificação englobe produtos que vão além da cachaça, as conclusões que foram alcançadas neste estudo possibilitam aos empresários do setor, os agentes envolvidos no 
macroambiente da internacionalização, agentes associados à órgãos públicos de apoio à exportação e estudantes universitários desta área de interesse, ter uma visão mais ampla e detalhada sobre o atual cenário das importações e exportações do setor.

Concluiu-se que, para o SH 220840, a participação das exportações brasileiras no âmbito mundial, e as exportações paraibanas no âmbito nacional, ainda fica muito aquém em relação à sua capacidade produtiva.

Por fim, esta pesquisa pode ser considerada como os passos iniciais para um melhor entendimento sobre o processo de internacionalização das cachaças paraibanas nos mercados alemão e paraguaio. É importante ressaltar que para estudos futuros, além dos aspectos que foram abordados nesta pesquisa, deve-se procurar atualizar o período de análise e considerar que existem outros aspectos que devem ser vistos quanto à decisão do mercado-alvo, que englobam costumes, questões culturais, barreiras comerciais, aspectos essenciais para a exportação dos produtos e outros conhecimentos acerca do mercado importador.

\section{REFERÊNCIAS}

ANDERSEN, O. Internationalization and New Market Entry: A review of theories and concepts. Management International Review, n. 1, v.37, p.27-42, 1997.

APEX BRASIL. Agência Brasileira de Promoção de Exportações e Investimentos. Disponível em: <http://www.apexbrasil.com.br >. Acesso em: 30 de julho de 2018.

APEX BRASIL. Qualifique sua empresa - PEIEX, 2018. Disponível em: <http://www.apexbrasil.com.br/qualifique-sua-empresa-peiex>. Acesso em: 29 de julho de 2018.

ASSOCIAÇÃO BRASILEIRA DAS INDÚSTRIAS DE ALIMENTAÇÃO - ABIA. Números do setor - $\quad$ Faturamento. Disponível em: <https://www.abia.org.br/vsn/anexos/faturamento2016.pdf>. Acesso em: 31 de julho de 2018.

BANCO DO NORDESTE - BNB, 2018. In: Caderno Setorial ETENE. Disponível em: <https://www.bnb.gov.br/documents/80223/1527922/bebidas.pdf/f4fbacee-fcc2-1302-fe82524cd8091422>. Acesso em: 30 de julho de 2018.

BARNEY, J. Firm Resources and Sustained Competitive Advantage. Journal of Management, v. 17, n. 1, p. 99-120, 1991.

BUCKLEY, P. J.; CASSON, M. C. The future of the multinational enterprise. London: Macmillan, 1976. 
CACHAÇA PARAIBANA. A Paraíba é um dos maiores produtores de cachaça artesanal do país, 2018. Disponível em: <https://cachacariaparaibana.com/a-paraiba-e-um-dos-maiores-produtoresde-cachaca-artesanal-do-pais/>. Acesso em: 31 de julho de 2018.

CARNEIRO, J.; DIB, L.A. Avaliação comparativa do escopo descritivo e explanatório dos principais modelos de internacionalização de empresas. Internext, v. 2, n. 1, p. 1-25, 2007.

COMEX STAT. Estatísticas de Comércio Exterior do Brasil. Disponível em: <http://comexstat.mdic.gov.br>. Acesso em: 14 de julho de 2018

COMTRADE. Repositório de Estatísticas oficiais de comércio internacional. Disponível em: < https://comtrade.un.org/data/>. Acesso em: 14 de julho de 2018

COUTINHO, E.P. Dinâmica da modernização do setor de produção de aguardente de cana-deaçúcar no Brasil: construindo uma cachaça de qualidade. 2001. Tese (Doutorado em Engenharia da Produção) - Universidade Federal do Rio de Janeiro, Rio de Janeiro.

COVIELLO, N.E.; MUNRO, H.J. Growing the entrepreneurial firm: networking for international market development. European Journal of Marketing, v. 29, n. 7, p. 49-61, 1995.

DUNNING, J. H. The Eclectic (OLI) Paradigm of International Production: Past, Present and Future. International Journal of the Economics of Business, v. 8, p. 173-190, 2001.

DUNNING, J. H. The Eclectic Paradigm of International Production: A Restatement and Some Possible Extensions. Journal of International Business Studies, 1988.

DUNNING, J. H. The Eclectic Paradigm of International Production: A Personal Perspective. In: C. N. Pitelis; R. Sugden (Orgs.); The nature of the transnational firm. 2o ed., p.119- 139, 2000. New York: Routledge.

DUNNING, J. H. Trade, Location of Economic Activity and The Multinational Enterprise: A Search for an Eclectic Approach. In: OHLIN, B.; HESSELBORN, P.; WUKMAN, P.; The International Allocation of Economic Activity. Londres: Macmillian, 1977.

HEMAIS, C. A.; HILAL, A. V. G. Teorias, paradigmas e tendências em negócios internacionais: de Hymer ao empreendedorismo. O desafio dos mercados externos: teoria e prática na internacionalização da firma. Volume I. p.17-39, 2004.

HÖRNELL, E.; VAHLNE, J.; WIEDERSHEIM-PAUL, F. Export and foreign establishments. Stockholm: Almqvist \& Wicksell, 1973.

HÖRNELL, E.; VAHLNE, J.; WIEDERSHEIM-PAUL, F. O processo de internacionalização na ótica da Escola Nórdica: evidências empíricas em empresas brasileiras. Revista de Administração Contemporânea, v. 7, n. 1, p. 109-204, 2003.

IBRAC. Instituto Brasileiro da Cachaça. Disponível em: 〈http://www.ibrac.net/>. Acesso em: 20 de junho de 2018. 
INCUBADORA TECNOLÓGICA DE EMPREENDIMENTOS CRIATIVOS E INOVADORES - ITCG. Paraíba recebe Programa de Qualificação para Exportação (PEIEX), 2017. Disponível em: <http://itcg.org.br/2017/04/07/paraiba-recebe-programa-de-qualificacao-para-exportacao-peiex/> . Acesso em: 30 de julho de 2018.

INVEST\&EXPORT BRASIL. Como Exportar Paraguai, 2016. Disponível em: < https://investexportbrasil.dpr.gov.br/arquivos/Publicacoes/ComoExportar/CEXParaguai.pdf>.

Acesso em: 30 de julho de 2018.

INVEST\&EXPORT BRASIL. Feiras no exterior. Disponível em: $<$ https://investexportbrasil.dpr.gov.br/FeirasExterior/Busca/frmBuscaFeiraExterior.aspx >. Acesso em: 29 de julho de 2018.

INVEST\&EXPORT BRASIL. Guia de Comércio Exterior e Investimento. Disponível em: $<$ http://www.investexportbrasil.gov.br>. Acesso em: 31 de julho de 2018.

INVEST\&EXPORT BRASIL. O Mercado Alemão para Cachaça Brasileira, 2016. Disponível em: <https://investexportbrasil.dpr.gov.br/Arquivos/PesquisasMercado/PMR1330000116.pdf>. Acesso em: 30 de julho de 2018.

JOHANSON, J.; MATTSSON, L.G. Internationalisation in Industrial Systems - A Network Approach. Hood and Vahlne (eds): Strategies in Global Competition, o. 287-314, 1988.

JOHANSON, J.; VAHLNE, J. E. The Internationalization process of the firm: a model of knowledge development and increasing foreign Market commitments. Journal of International Business Studies, v. 8, n. 1, p. 25-34, 1977.

JOHANSON, J.; WIEDERSHEIMPAUL, F. The Internationalization of the Firm - Four Swedish Cases. Journal of Management Studies, v. 12, n. 3, p. 305-322, 1975.

MDIC. Ministério da Indústria, Comércio Exterior e Serviços. Disponível em: <http://www.mdic.gov.br/>. Acesso em: 31 de julho de 2018.

MERRIAM, S. B. Qualitative research and case study applications in education, San Francisco, Jossey-Bass, 1998.

MESQUITA, R. As melhores cachaças do Brasil são eleitas pelo $3^{\circ}$ Ranking da Cúpula. Estadão, 2018. Disponível em: <https://paladar.estadao.com.br/noticias/bebida,3-ranking-da-cupula-dacachaca-elege-as-melhores-do-brasil,70002172971>. Acesso em: 31 julho 2018.

MINISTÉRIO DA AGRICULTURA, PECUÁRIA E ABASTECIMENTO - MAPA. Feiras Internacionais. 2018. Disponível em: <http://www.agricultura.gov.br/assuntos/relacoesinternacionais/eventos-internacionais/feiras-internacionais/feiras-2018>. Acesso em: 29 de julho de 2018.

PATTON, M.Q. Qualitative research and evaluation methods, 3rd edition, Thousand Oaks, SAGE Publications, 2002. 
SEBRAE. Relatório de Gestão - Sebrae Paraíba, 2016. Disponível em: <https://m.sebrae.com.br/Sebrae/Portal\%20Sebrae/UFs/PB/Anexos/RELATORIO-DE-GESTAO2016.pdf>. Acesso em: 30 de julho de 2018.

SILVA, A. A Paraíba está entre os maiores produtores de cachaça do país, 2017. Disponível em: <http://www.ct.ufpb.br/lpfd/contents/noticias/a-paraiba-esta-entre-os-maiores-produtores-decachaca-do-pais>. Acesso em: 31 de julho de 2018.

TRADE MAP. Trade statistics for international business development. Disponível em: <http://www.trademap.org>. Acesso em: 15 de julho de 2018.

VIDAL, M.F.; GONÇALVES, M.F. Produção de cachaça na área de jurisdição do BNB: mercado e estrutura da cadeia produtiva. In: CONGRESSO BRASILEIRO DA SOCIEDADE DE ECONOMIA, ADMINISTRAÇÃO E SOCIOLOGIA RURAL, 46, 2008, Rio Branco, Acre. Anais... Rio Branco, Acre: FAAO, 2008, p. 21.

WELCH, Lawrence S.; LUOSTARINEN, Reijo. Internationalization: Evolution of a concept. Journal of General Management, n. 1, v. 14, p. 36-64, 1999.

WILLIAMSON, O.E. Comparative Economic Organization: The Analysis of Discrete Structural Alternatives. Administrative Science Quarterly, v. 36, n. 2, p; 269-296, 1991.

YIN, R. K. E. Estudo de Caso: planejamento e método. Porto Alegre: Bookman, 2010. 